\title{
Evasão e abandono escolar: os desafios de conter seu avanço, as causas e consequências- estudo de caso na Escola Municipal "João Mendonça", em Teixeira
}

\section{de Freitas- Bahia}

\author{
School evasion and abandonment: the challenges of containing its advance, the causes and \\ consequences- case study in the Municipal School "João Mendonça", in Teixeira de Freitas- Bahia \\ Evasión y abandono escolar: los retos de contener su avance, las causas y consecuencias- estudio de \\ caso en la Escuela Municipal “João Mendonça”, en Teixeira de Freitas- Bahia
}

Recebido: 28/01/2021 | Revisado: 03/03/2021 | Aceito: 03/04/2021 | Publicado: 11/04/2021

\author{
Débora Zago Bissaro \\ ORCID: https://orcid.org/0000-0003-3588-3176 \\ Prefeitura Municipal de Teixeira de Freitas, Brasil \\ E-mail: dzbissaro@gmail.com \\ Ednete Morais Costa Elias \\ ORCID: https://orcid.org/0000-0002-2861-9169 \\ Universidade Federal do Espírito Santo, Brasil \\ E-mail: emce12@gmail.com \\ Soane Lopes Becevelli \\ ORCID: https://orcid.org/0000-0001-6286-1998 \\ Faculdades Integradas do Extremo Sul da Bahia, Brasil \\ E-mail: slsadv03@gmail.com \\ Suzete Morais Costa \\ ORCID: https://orcid.org/0000-0003-4782-4237 \\ Prefeitura Municipal de Itamaraju, Brasil \\ E-mail: suzemorais@hotmail.com \\ Tânia Gomes Ferreira da Costa \\ ORCID: https://orcid.org/0000-0003-2134-3179 \\ Prefeitura Municipal de Itamaraju, Brasil \\ E-mail: glfcferreira@gmail.com
}

\begin{abstract}
Resumo
Em pleno século XXI, o problema da evasão e abandono escolar ainda não foi mitigado e, consequentemente, pelo que se tem apurado, ainda vai levar muito tempo para ser extinto da educação formal. Este trabalho teve como objetivo compreender de que forma acontece a evasão e o abandono escolar, quais os desafios enfrentados pelas instituições de educação para o contingenciamento de seus avanços e a identificação de suas causas e consequências. A metodologia utilizada de acordo com os procedimentos de coleta foi um Estudo de Caso, vinculado a uma pesquisa de campo, sendo o lócus da pesquisa a Escola Municipal "João Mendonça", localizada na Cidade de Teixeira de Freitas-Bahia. Quanto à natureza dos dados configurou-se como uma pesquisa qualitativa. Os sujeitos da pesquisa foram os alunos(as) da Educação Básica (Ensino Fundamental II e Educação de Jovens e Adultos-EJA), com um recorte temporal dos anos de 2014 a 2018. A pesquisa se justificou para que se possa conhecer e se trabalhar na erradicação desse problema que acomete as instituições de ensino, atingindo crianças, adolescentes, jovens e adultos, a despeito da legislação pátria, com políticas públicas referentes ao esse problema. Não houve aqui a intenção de se esgotar o tema, mas trazer uma reflexão junto aos teóricos, pesquisadores e educadores que já vêm tratando do tema e que se extinga de uma vez a disseminação desse mal que atinge a educação no Brasil.
\end{abstract}

Palavras-chave: Evasão e abandono escolar; Políticas públicas; Educação básica; Alunos.

\begin{abstract}
In the middle of the 21st century, the problem of dropping out and dropping out of school has not yet been mitigated and, consequently, from what has been determined, it will still take a long time to be extinguished from formal education. This work aimed to understand how school dropout and dropout occurs, what are the challenges faced by educational institutions in order to limit their progress and identify their causes and consequences. The methodology used in accordance with the collection procedures was a Case Study, linked to a field research, with the research site
\end{abstract}


being the Municipal School "João Mendonça", located in the City of Teixeira de Freitas-Bahia. As for the nature of the data, it was configured as a qualitative research. The subjects of the research were students of Basic Education (Elementary Education II and Education of Youth and Adults-EJA), with a time frame from the years 2014 to 2018. The research was justified so that it is possible to know and work in the eradication of this problem that affects educational institutions, affecting children, adolescents, young people and adults, in spite of the national legislation, with public policies related to this problem. There was no intention here to exhaust the theme, but to bring a reflection with the theoreticians, researchers and educators who have already been dealing with the theme and that the dissemination of this evil that affects education in Brazil is extinguished once and for all.

Keywords: Dropout and dropout; Public policy; Basic education; Students.

\section{Resumen}

A mediados del siglo XXI, el problema de la deserción y la deserción escolar aún no se ha mitigado y, en consecuencia, por lo que se ha determinado, aún será necesario mucho tiempo para que se extinga de la educación formal. Este trabajo tuvo como objetivo comprender cómo se produce la deserción y la deserción escolar, cuáles son los desafíos que enfrentan las instituciones educativas para limitar su avance e identificar sus causas y consecuencias. La metodología utilizada de acuerdo con los procedimientos de recolección fue un Estudio de Caso, vinculado a una investigación de campo, siendo el sitio de investigación la Escuela Municipal "João Mendonça”, ubicada en la Ciudad de Teixeira de Freitas-Bahia. En cuanto a la naturaleza de los datos, se configuró como una investigación cualitativa. Los sujetos de la investigación fueron estudiantes de Educación Básica (Educación Primaria II y Educación de Jóvenes y Adultos-EJA), con un marco temporal de los años 2014 a 2018. La investigación se justificó para que sea posible conocer y trabajar en la Erradicación de este problema que afecta a las instituciones educativas, afectando a niños, adolescentes, jóvenes y adultos, a pesar de la legislación nacional, con políticas públicas relacionadas con este problema. Aquí no se pretendía agotar el tema, sino traer una reflexión con los teóricos, investigadores y educadores que ya venían abordando el tema y que la difusión de este mal que afecta a la educación en Brasil se extingue de una vez por todas.

Palabras clave: Abandono y abandono escolar; Políticas públicas; Educación básica; Estudiantes.

\section{Introdução}

A evasão escolar é um tema que traz em seu contexto diversas formas de se apresentar. Configura-se como um problema muito sério na educação brasileira, principalmente no Ensino Médio, mas que tem suas ramificações no Ensino Fundamental II, no Ensino Superior, atingindo principalmente a Educação de Jovens e Adultos (EJA). Portanto, não tem seriação que esteja incólume desse evento conjuntural. Digiácomo (2005, s.p.) ressalta que:

A evasão escolar é um problema crônico em todo o Brasil, sendo muitas vezes passivamente assimilada e tolerada por escolas e sistemas de ensino, que chegam ao cúmulo de admitirem a matrícula de um número mais elevado de alunos por turma do que o adequado já contando com a "desistência" de muitos ao longo do ano letivo.

Porém, os problemas que serão elencados no decorrer desta pesquisa não são de responsabilidade somente do sistema de ensino, mas também da omissão dos governantes, da falta de políticas públicas, da estrutura familiar e da falta de cumprimento da legislação pertinente à educação, que de acordo com Rumberger (1995 como citado em Silva Filho e Araújo, 2017 , p. 44):

Para Rumberger (1995 e 2008), pesquisador americano, a chave da compreensão e solução da evasão é encontrar as causas do problema, mas essas causas de forma análoga a outros processos do desempenho escolar têm influência de um conjunto de fatores, como o estudante, a família, a escola e a comunidade em que vive. Revisando diversas pesquisas sobre as causas que levam à evasão, esse autor consegue identificar como problema duas perspectivas: uma individual, que envolve o estudante e as circunstâncias de seu percurso escolar; e outra institucional, que leva em conta a família, a escola, a comunidade e os grupos de amigos. Ainda podem ser verificadas diferentes teorias que abordam a evasão escolar. Algumas citam a existência de dois tipos principais de engajamento: o escolar (acadêmico ou aprendizagem) e o social (relacionamento com os colegas, com os professores e com os demais membros da comunidade escolar). Essas duas formas são determinantes para a decisão de evadir ou permanecer na escola (Rumberger, 1995, 2008). 
De acordo com o pensamento do autor americano, várias são as causas que impulsionam os casos de evasão e abandono escolar. Não existem fatores isolados. É um entrincheiramento de situações, de procedimentos e de ocorrências que vão incidir nesses eventos.

Neste trabalho faremos uma abordagem sobre a evasão e abandono escolar, como se dá a sua ocorrência, quais suas causas e as consequências dentro de um processo lento e quase imperceptível, com análise dos seus instrumentos de contenção e sua vinculação com possíveis problemas sociais e a ausência de políticas públicas eficientes para promoção e permanência da criança, do adolescente, dos jovens e adultos na escola.

Esta pesquisa tem como objetivo geral compreender como acontece a evasão e o abandono escolar, quais os desafios enfrentados pela escola, sociedade e o papel do Estado no contingenciamento dos seus avanços, bem como identificar as suas causas e consequências.

Quanto aos objetivos específicos a proposição é identificar as causas que levam crianças, adolescentes, jovens e adultos a evadirem e abandonarem a escola; evidenciar a legislação que ampara e estatui sobre a educação; conhecer as ações e as políticas públicas afirmativas para o combate a evasão escolar; e, analisar o papel do Estado, da Família e da Sociedade no enfrentamento e combate à evasão e ao abandono escolar.

$\mathrm{O}$ tema em estudo se justifica pelo fato de que a educação brasileira tem vários entraves que dificultam a efetivação e universalização de educação para todos, como estatuem a Constituição Federal e a legislação infraconstitucional, a exemplo do Estatuto da Criança e do Adolescente - ECA, Lei 8.069/90 e da Lei das diretrizes e Bases da Educação Brasileira - LDBEN, Lei 9394/96, em que o Estado, a Família e a Sociedade podem ser um tripé de amparo e efetivação do direito de permanência na escola.

Enfatiza-se essa proposição visto que as políticas públicas engendradas para melhor atendimento à comunidade escolar, no sentido geral, têm um processo histórico e a legislação brasileira ao trazer a educação com vetor de desenvolvimento das pessoas, tem na evasão e o abandono escolar dois problemas que vêm na contramão deste propósito e se reverberam no descaso que se disseminam na Educação Básica.

O Estado, a Sociedade e a Família são o tripé que ancoram e dão sustentabilidade ao exercício do direito à educação de cada indivíduo, principalmente as crianças e os adolescentes, pelo fato de serem vulneráveis e não terem maturidade suficiente para requerer tal direito. É neste contexto de educação, de direitos e de apoio ou não das famílias, do Estado e da Sociedade que têm pertinência os temas evasão e abandono escolar.

\section{Metodologia}

A metodologia utilizada de acordo com os procedimentos de coleta foi um Estudo de Caso, vinculado a uma pesquisa de campo, tendo como objeto da pesquisa a Escola Municipal "João Mendonça”, localizada na Cidade de Teixeira de FreitasBahia. Segundo Gil (2010, p. 37):

O estudo de caso é uma modalidade de pesquisa amplamente utilizada nas ciências biomédicas e sociais. Consiste no estudo profundo e exaustivo de um ou poucos objetos, de maneira que permita seu amplo e detalhado conhecimento, tarefa impossível mediante outros delineamentos já considerados.

Segundo a natureza dos dados, configurou-se como uma pesquisa qualitativa. A pesquisa qualitativa objetiva elucidar a proposta envidada no tema, pois nos dá suporte no processo de coleta de dados, na abordagem com os sujeitos da pesquisa, bem como para se entender melhor a subjetividade de cada ator social envolvido. Outro fator a se levar em conta é a flexibilidade em sua condução, não deixando o pesquisador engessado. De acordo com Córdova e Silveira (2009, p. 31): 
As características da pesquisa qualitativa são: objetivação do fenômeno; hierarquização das ações de descrever, compreender, explicar, precisão das relações entre o global e o local em determinado fenômeno; observância das diferenças entre o mundo social e o mundo natural; respeito ao caráter interativo entre os objetivos buscados pelos investigadores, suas orientações teóricas e seus dados empíricos; busca de resultados os mais fidedignos possíveis; oposição ao pressuposto que defende um modelo único de pesquisa para todas as ciências.

Quanto aos sujeitos da pesquisa tivemos os alunos e as alunas da Educação Básica (Ensino Fundamental II e Educação de Jovens e Adultos-EJA); com um recorte temporal dos anos de 2014 a 2018, com apresentação de gráficos deste período com números dos casos de evasão, com as respectivas seriações.

De acordo esses mesmos procedimentos trata-se de uma pesquisa bibliográfica, pois foram coletados dados de revistas eletrônicas, livros, sites, teses, dissertações, etc. Portanto, Gil (2010, p. 29) infere que "praticamente toda pesquisa acadêmica requer em algum momento a realização de trabalho que pode ser caracterizado como pesquisa bibliográfica".

Por fim, este trabalho tem uma pesquisa documental, pois foram analisados documentos da escola em estudo, como por exemplo, as pautas de presença dos alunos, e que ao fazermos o cômputo dos casos de evasão, fomos detectando um número expressivo de alunos com problemas familiares, profissionais (alunos da EJA) e, que consequentemente incidem na desistência de estudar e avançar para as séries seguintes.

\section{Evasão e Abandono Escolar, Conceito, Formas e Características}

A priori é tempestivo um conceito fidedigno de evasão. Mas o que significa o termo evasão? De acordo com o Ferreira (2001, p. 302): "evasão sf. Ato de evadir-se; fuga".

Portanto, percebemos que o aluno quando está matriculado e sai da escola e para esta não volta mais, ele evadiu-se. E esta prática é recorrente aqui no Brasil, mesmo com leis tão garantidoras, mas com variados motivos e que muitas vezes escapam do alcance legal.

No entanto, Riffel e Malacarne (2010), têm mais um conceito sobre evasão que diz: compreende-se o ato de evadir-se, fugir, abandonar; sair, desistir; não permanecer em algum lugar. Quando se trata de evasão escolar, entende-se a fuga ou abandono da escola em função da realização de outra atividade.

A evasão escolar é um acontecimento educacional onde o educando deixa de frequentar a escola no período em que a mesma é obrigatória. A Lei de Diretrizes e Bases da Educação Nacional 9.394/96 e o Estatuto da Criança e do Adolescente (1990) orientam aos estabelecimentos de ensino que efetuem um controle diário da presença de seu alunado e quando ocorre uma ausência que supere a três dias deverá entrar em contato com os responsáveis pelo educando, e se não solucionado o caso deverá notificar o Conselho Tutelar e a Vara da Infância e Juventude de sua cidade. (Mendes, 2016, p. 5 e 6).

O Sistema de Ensino brasileiro traz em seu contexto muitas falhas que ensejam problemas para a sociedade e para aqueles que procuram a escola, mitigando o direito à educação, contido na Constituição Federal e nas leis infraconstitucionais.

Durante muito tempo, a educação no Brasil, estatuída de maneira tímida nas Constituições até então existentes, não atendia a demanda da população, no sentido de abastecer as necessidades provenientes das exigências de direito daqueles que procuravam as instituições de ensino em busca de uma vaga para estudar.

Somente com o advento da CF de 1988, a educação passa a ser um direito fundamental, intransferível e subjetivo. Souza (2010, p. 19), enfatiza sobre a educação como direito fundamental:

Dentre os direitos fundamentais, a educação merece especial destaque.

De fato, como processo de reconstrução da experiência e atributo da pessoa humana, a educação é autêntico direito da personalidade, motivo que deve ser acessível a todos. 
Sua estrutura surgiu, enquanto marco histórico inserido na evolução dos direitos humanos fundamentais, na segunda geração, dos denominados direitos sociais, consoante acima exposto.

Não obstante, a importância da educação a faz integrar, também a fase dos direitos difusos, a partir do momento em que os valores como a fraternidade, a igualdade e a liberdade, pilares da dignidade da pessoa humana e da construção efetiva de um Estado Democrático de Direito, somente podem consolidar-se no bojo de uma sociedade apta a enfrentar as diversas complexidades advindas do processo de globalização, cuja premissa básica e indispensável é a adequada formação educacional do povo.

É imprescindível entender que a educação deve permear as ações dos seres humanos na conquista dos seus objetivos, no ir e vir dos seus passos e na consolidação dos seus direitos sociais.

Mesmo a educação sendo um direito inalienável, constante no rol dos direitos sociais, este vigente na Constituição Federal do Brasil, muito tem que ser feito para que as crianças e adolescentes tenham esse direito que é uma garantia e que se efetive.

A CF/1988, no seu Título II, Capítulo II, Art. 6º prescreve o seguinte: "São direitos sociais a educação, a saúde, o trabalho, o lazer, a segurança, a previdência social, a proteção à maternidade e à infância, a assistência aos desamparados, na forma desta Constituição". (Brasil, 1988, grifo nosso).

No entanto, ainda está muito longe o dia que possivelmente esta legislação acerca da educ ação como direito de todos, seja respeitada e efetivada de fato, pois são muitos os casos de pessoas de todas as idades, raças, sexo e cor que ainda não conseguem adentrar-se numa instituição de ensino, para exercer tal direito.

É pertinente entendermos que há uma diferença entre evasão escolar e abandono, pois a exegese dos dois termos parece similar, mas significa situações diferentes, pois de acordo com o Instituto Nacional de Estudos e Pesquisas Educacionais Anísio Teixeira/INEP (2010) “o abandono se dá quando a criança está matriculada e para de frequentar a escola naquele ano, mas ela volta no ano seguinte. Na evasão ela abandona a escola e não se matricula no ano subsequente". São vários os fatores que dão incidência à evasão escolar, de acordo com Silva Filho e Araújo (2017, p. 39):

Fatores intrínsecos e extrínsecos à escola, como drogas, sucessivas reprovações, prostituição, falta de incentivo da família e da escola, excesso de conteúdo escolar, alcoolismo, vandalismo, falta de formação de valores e preparo para o mundo do trabalho influenciam diretamente nas atitudes dos alunos que se afastam da escola.

A participação dos professores, diretores e coordenadores escolares, muitas vezes não consegue inibir esse evento, pois os pais como (ir)responsáveis, também vítima do sistema socioeconômico e cultural do País, se veem desobrigados na conduta de zelar e educar os seus filhos numa instituição de ensino. Nesse entendimento, tem o papel do governo, com políticas públicas ineficazes. "A evasão escolar tem sido historicamente tema de debate e reflexões da educação pública brasileira manente entre os educadores. O que se discute é o papel da família, da escola e das políticas públicas em relação à vida escolar da criança". (Burigo, 2014).

Muitos pais não participam da vida das suas crianças e adolescentes, deixando-as à míngua de uma vida empobrecida culturalmente e por consequência, sem uma visão de futuro mais próspero e com menos chances em relação aos que têm pais comprometidos.

A participação dos pais na aprendizagem escolar é de suma importância, dá aos filhos segurança e exemplo. É do conhecimento de todos que ao longo da segunda metade do século vinte, a sociedade passou por mudanças estruturais que afetou de forma indelével a família, que teve em o seu núcleo central, a figura do pai (chefe de família), praticamente extinta, uma vez que a mulher ao se colocar no mercado de trabalho assume uma nova representação na antiga ordem familiar. Porém, essa mulher, se por lado divide, quando não, assume, a manutenção econômica e estrutural da família, na maioria das vezes, não rompeu, ainda, as representações dos papeis de organização dos fazeres doméstico. Assim, toda a antiga retaguarda que a mulher (mãe) dava aos filhos, garantindo uma educação básica para as crianças, de forma que quando elas fossem à escola possuíssem um comportamento mínimo de 
convívio em grupo, hoje já não é a regra. Isso, somados as novas configurações familiares, relacionadas a separações dos casais, casamento homoafetivos, pais que estão encarcerados, dependentes químicos e alcoolistas, e outras expressões das questões sociais, se revelam como elementos centrais, numa leitura mais próxima da realidade que levam a criança e o jovem a se evadirem da escola. (Burigo, 2014, p. 18 e 19)

A evasão escolar é um processo de acontecimentos preliminares que incidem em sua efetivação. A escola ao perceber que um aluno é faltoso e sem justificativas deve acionar a família. Nesse primeiro momento é de extrema cautela uma investigação das causas que podem acometer a vida desse aluno e ter como desfecho a evasão. Souza (2010, p. 42), diz o seguinte:

Vindo o aluno a se ausentar rotineiramente das atividades escolares, é obrigação dos dirigentes de ensino perquirir, junto à família, os motivos das faltas.

Observados os fatos ensejadores das reiteradas ausências, o Poder Público tem o dever de adotar medidas necessárias para a reversão do quadro, atacando suas causas pela adoção de programas de apoio sócio-familiar, de alimentação, sanitários ou outros que se mostrem imprescindíveis para que o problema seja sanado.

Caso as medidas adotadas pelo Poder Público venham a se mostrar insuficientes, deverá o dirigente de ensino comunicar o fato ao Conselho Tutelar, consoante o disposto no artigo 56, II, do Estatuto da Criança e do Adolescente, para que este atue junto à família, em virtude da regra inserta no artigo 136, I, c. c. o artigo 98, da Lei Federal n. $8069 / 90$.

Todas as medidas cabíveis para manter a criança e o adolescente, estes menores de idade, e, portanto, sob a responsabilidade dos pais, devem ser tomadas para que a lei se cumpra e o direito de frequentar a escola seja deveras cumprido.

Mostrando-se, ainda assim, insuficiente a medida, o Conselho Tutelar deverá transmitir a situação ao Ministério Público, para as providências cabíveis quanto à evasão escolar, inclusive com a possibilidade da propositura de ação visando à destituição do poder familiar. (Souza, 2010, p. 43):

Para que a lei seja cumprida na sua íntegra, a Lei 10.287, de 20 de setembro de 2001 ao seu turno veio inserir ao artigo 12- VIII da LDB 9394/96 o seguinte dispositivo:

\begin{abstract}
“Os estabelecimentos de ensino, respeitadas as normas comuns e as do seu sistema de ensino, terão a incumbência de: notificar ao Conselho Tutelar do Município, ao juiz competente da Comarca e ao respectivo representante do Ministério Público a relação dos alunos que apresentem quantidade de faltas acima de cinquenta por cento do percentual permitido em lei."
\end{abstract}

Portanto, é imperativo afirmar que no Brasil o caminho para o abrandamento e a extinção definitiva da evasão e suas causas eminentes ainda é de difícil acesso, pois enseja diversos fatores que possam coibir o afastamento definitivo de estudantes do setor escolar. Cabe a escola enquanto instituição de ensino, como estatui o Estatuto da Criança e do Adolescente/90, notificar e informar ao Conselho Tutelar os casos de Evasão Escolar, quando o caso fugir-lhe a sua alçada. Brasil, (Lei 8.069/1990):

Art. 56. Os dirigentes de estabelecimentos de ensino fundamental comunicarão ao Conselho Tutelar os casos de: $[\ldots]$

II - reiteração de faltas injustificadas e de evasão escolar, esgotados os recursos escolares; (Grifo Nosso) $[\ldots]$.

À letra da lei a escola precisa estar atenta aos casos inerentes à evasão escolar, para que estes sejam abrandados e posteriormente extintos do contexto educacional. Com Políticas Públicas ainda tão incipientes, o governo, a sociedade e, 
principalmente a família ainda não tomaram consciência de que o caso é muito sério e que precisa da atuação coletiva no combate a esse problema que assola a educação como um todo.

Logo surgiu uma verdadeira "enxurrada" de expedientes, encaminhados apressadamente pelas escolas, às autoridades públicas indicadas no texto legal transcrito, contendo listas muitas vezes bastante extensas de alunos infrequentes, alguns, não é preciso dizer, com percentual de faltas muito superior ao máximo permitido em lei, que é de 25\% (vinte e cinco por cento) do total de horas letivas (art.24, inciso VI da Lei $\mathrm{n}^{\circ}$ 9.394/96).

Tal cenário nos leva a concluir que boa parte dos dirigentes de estabelecimentos de ensino somente se deram conta da necessidade de tomarem medidas no sentido de providenciarem o retorno de seus alunos infrequentes aos bancos escolares com a promulgação do texto legal acima transcrito, quando na verdade, consoante alhures mencionado, tal obrigação já constava do ordenamento jurídico vigente, inclusive da própria Lei de Diretrizes e Bases da Educação Nacional, bem como de nossa Constituição Federal. (Digiácomo, 2005).

Diante do exposto acima, além de um compromisso moral dos estabelecimentos de ensino em notificar os casos de faltas injustificadas e possível abandono ou mesmo evasão escolar, é uma obrigatoriedade legal, pois os dirigentes escolares, professores, corpo administrativo e quem mais de direito, não podem se isentar de cumprir o que está estatuído no ordenamento jurídico brasileiro.

\section{O papel da Família, da Escola e do Estado na Contenção e Abrandamento da Evasão e}

\section{Abandono Escolar.}

No contexto educacional, o aprendizado é um instrumento que precisa de parcerias para acontecer efetivamente. Dentre estas parcerias, a família é o grupo social mais importante, a priori, para que toda a função de ensinar e aprender aconteça fluidamente, e seja um sucesso. Segundo Oliveira (2005, p. 64):

A família é o primeiro grupo social a que pertencemos. É um tipo de agrupamento social cuja estrutura, em alguns aspectos, varia no tempo e no espaço. Essa variação pode ser quanto ao número de casamentos, quanto à forma de casamento e quanto ao tipo de família e autoridade.

Sabemos que muitas famílias, principalmente das instituições públicas de ensino, mesmo com vontade de ter os filhos estudando, numa educação formal, têm outras prioridades que se sobrepõem ao desejo de vê-los a caminho da escola. Além das prioridades, vêm as dificuldades, que são ainda maiores.

Por muito tempo, a família desempenhou o papel principal no processo de educação. À medida que o tempo passa, porém, embora continue exercendo grande influência na formação das crianças e dos jovens como grande agência de socialização, ela vem perdendo bastante das suas funções pedagógicas. (Oliveira, 2005, p. 65).

Cabe à família, no seu papel de provedora, estimular e motivar seus filhos e conduzi-los no caminho da educação tanto informal, mas também na educação formal, escolarizada.

A família deve ser uma parceira contumaz da escola no que tange a educação dos seus filhos. Esta relação de parceria entre família e escola, ajuda a criança a superar seus medos, suas incertezas e a conduz para um aprendizado com mais autonomia e com experiências mais consistentes.

Uma ligação estreita e continuada entre os professores e os pais leva, pois a muita coisa que a uma informação mútua: este intercâmbio acaba resultando em ajuda recíproca e, frequentemente, em aperfeiçoamento real dos métodos. Ao aproximar a escola da vida ou das preocupações profissionais dos pais, e ao proporcionar, reciprocamente, aos pais um interesse pelas coisas da escola chega-se até mesmo a uma divisão de responsabilidades [...] (Piaget, 2007, p.50). 
No quadro das prioridades, elencamos a família numerosa e que precisa do irmão ou irmã mais velho(a) para cuidar de outros irmãos; filhos que precisam trabalhar para ajudar no sustento da casa; e, ajudar nos afazeres domésticos, no caso das meninas, pois a mãe, geralmente trabalha fora.

Por essa razão, escola e família possuem funções que se assemelham e se aproximam. Funções estas que poderiam se resumir, sinteticamente, em como proteger e educar, dar autonomia à criança, poder permanecer no espaço da troca, sem cair na armadilha da disputa, buscando acertos e corrigindo erros. (Silva; Araújo, 2014, p. 26).

As necessidades socioeconômicas que as famílias passam e que impedem de manter os filhos na escola vêm de longe e assola esse contexto social tão maltratado, que prematuramente arrancam crianças e adolescentes do seio da escola, pois a luta pela sobrevivência é árdua e inglória, além de necessária. Por isto, o papel do Estado através das políticas públicas, pode por certo ajudar as famílias na manutenção dos seus filhos na escola e assim evitar a evasão e o abandono escolar. Burigo (2014, p. 23) afirma o seguinte:

Quando o assunto é sobre a evasão escolar, estudos e pesquisas mostram que entre outras causas, às condições sociais desfavoráveis é a principal, assim expõe-se o aluno a violência e em alguns casos ao uso de produtos ilícitos, por isso a importância de existirem programas paralelos de assistência às famílias para assegurar, não só o ingresso, mas também a permanência do aluno na escola.

Muitos programas sociais foram arregimentados pelo Governo no intuito de abrandar os casos de evasão e abandono escolar, mas estes não chegam a abarcar todos os que estão em situação vulnerável. Muitos desses programas se perdem por falta de lisura de muitos administradores públicos ou por desconhecimento de quem tem realmente direito de exigir que se cumpram as leis que protegem tais direitos.

As políticas voltadas para a educação têm garantias, mas se resumem em segundo plano, pois não existe interesse em sua concretude por parte de vários segmentos do governo.

Kuroski (2013, p. 153), traz um quadro sinóptico sobre os programas do $\mathrm{FNDE}^{1}$, para que haja entendimento sobre os programas voltados para a educação básica, como incentivo de permanência das crianças e adolescentes na escola e que a evasão seja diminuída e por vezes extinta.

Esses programas elencados no quadro abaixo tem o fito de minimizar as mazelas oriundas de uma sequência de políticas públicas mal gerenciadas e com condução fora do alcance dos verdadeiros destinatários. Portanto, a intenção de trazermos estes programas é para que haja mais conhecimento e que se conheçam os direitos de crianças, adolescentes, jovens e adultos e que estes tenham acesso mais efetivo a tudo que lhes pertencem.

\footnotetext{
${ }^{1}$ É uma autarquia do MEC, responsável por prover recursos financeiros públicos e executar programas e ações educacionais e de assistência aos estudantes, para o desenvolvimento da educação, visando garantir a educação de qualidade a todas as crianças brasileiras (Kuroski, 2013, p. 152).
} 
Quadro 1. Programas do FNDE.

\begin{tabular}{|l|l|l|}
\hline \multicolumn{1}{|c|}{ ASSISTENCIA } & \multicolumn{1}{|c|}{ INFRAESTRUTURA } & \multicolumn{1}{c|}{ FINANCIAMENTO } \\
\hline $\begin{array}{l}\text { Programa Nacional de Alimentação } \\
\text { Escolar - PNAE }\end{array}$ & $\begin{array}{l}\text { Programa Dinheiro Direto na Escola }- \\
\text { PDDE }\end{array}$ & $\begin{array}{l}\text { Fundo de Manutenção } \\
\text { Desenvolvimento da Educação Básica } \\
\text { e de Valorização dos Profissionais de } \\
\text { Educação - FUNDEB }\end{array}$ \\
\hline $\begin{array}{l}\text { Programas de Transporte (rural e } \\
\text { urbano) - PNTE-PNATE }\end{array}$ & $\begin{array}{l}\text { Programa Nacional Biblioteca da } \\
\text { Escola - PNBE }\end{array}$ & $\begin{array}{l}\text { Fundo de Financiamento ao Estudante } \\
\text { do Ensino Superior (FIES) }\end{array}$ \\
\hline $\begin{array}{l}\text { Programas do Livro } \\
\text { PNLD/PNLEM/PNLA }\end{array}$ & Informática na educação & $\begin{array}{l}\text { Programa Dinheiro Direto na Escola } \\
\text { (PDDE) }\end{array}$ \\
\hline $\begin{array}{l}\text { Programa Nacional Saúde do Escolar } \\
\text { PNSE) }\end{array}$ &
\end{tabular}

Fonte: Kuroski (2013, p. 153).

Qual é a função de cada programa? Esses programas ajudam na locomoção e transporte das crianças; na aquisição de livros didáticos em bibliotecas para que consigam conhecimento; na inclusão digital; e principalmente na merenda escolar, pois a falta de alimentação é uma das causas que impossibilitam a ida para a escola e a sua falta vai impactar na evasão escolar, pois muitos alunos sem condição econômica veem na escola uma forma de se alimentarem. É a forma reversa da evasão.

Evasão escolar é um caso muito sério, que deve ser acompanhado pelos pais, responsáveis, governo, escola e pela sociedade como um todo. É um trabalho árduo, que convoca a responsabilidade de todos os atores sociais, jurídicos e políticos para enveredarem nessa trincheira de combate à desistência da criança, do adolescente, do jovem e do adulto e que continuem a frequentar a escola.

As estatísticas são alarmantes, pois, por mais que se tente seguir o que é de vigência constitucional e infraconstitucional, os estabelecimentos de ensino na pessoa dos dirigentes educacionais, não conseguem minimizar as causas, nem as mazelas que sucumbem os estudantes e os fazem desistir de escola.

As situações são recorrentes e inexoravelmente a evasão chega, pois os problemas são infindos. A desigualdade social, a globalização neoliberal, as questões econômicas que muito cedo exigem mão de obra barata no mercado de trabalho, e a desestruturação familiar, tudo isso vem incidir num maior volume de estudantes dispersos, desmotivados e consequentemente fora do sistema escolar. De acordo com Silva Filho e Araújo (2017, p. 40):

O Censo Escolar de 2007, analisado pelo Instituto Nacional de Estudos e Pesquisas Educacionais Anísio Teixeira (Inep/MEC), afirma que a evasão escolar entre jovens é alarmante. Dos 3,6 milhões que se matriculam no ensino médio, apenas 1,8 milhão concluem esse grau. A taxa de evasão é de $13,3 \%$ no ensino médio contra $6,7 \%$, de $5^{\text {a a }} 8^{\mathrm{a}}$ série, e $3,2 \%$, de $1^{\text {a }}$ a $4^{\mathrm{a}}$ série. O Brasil tem, atualmente, 8,3 milhões de alunos no ensino médio, matriculados em 24 mil escolas - sendo 17 mil públicas - e metade destes, conforme o Ministério da Educação, não finalizam seus estudos (Brasil, 2007).

Com um índice de 24,3\%, o Brasil tem a terceira maior taxa de abandono escolar entre os 100 países com maior IDH (Índice de Desenvolvimento Humano), só atrás da Bósnia Herzegovina (26,8\%) e das ilhas de São Cristovam e Névis, no Caribe (26,5\%). Na América Latina, só Guatemala (35,2\%) e Nicarágua (51,6\%) têm taxas de evasão superiores.

Diante da alarmante estatística desenhada aqui no Brasil, feita pelo Ministério da Educação e Cultura - MEC, através do Instituto Nacional de Estudos e Pesquisas Educacionais Anísio Teixeira, - INEP, vimos que os dados são preocupantes, vez que as tomadas de decisão precisam ser mais eficazes. 
De um lado existe um núcleo familiar em constante decadência por fatores dantes elencados. Do outro lado uma educação com o ranço dos anos de retrocesso, que deixou o corpo docente sem muitos meios para agir, em prol desses meninos e meninas sem muitas perspectivas no seio familiar.

A escola não oferece muitos atrativos para manter os alunos na escola. Se a merenda escolar é um atrativo social, o Poder Público não cumpre seu papel à risca, como determina a lei, pois sempre existiu a burla e os desvios de verba que não fazem com que as escolas se abasteçam desse item. Os problemas são contumazes, reincidentes e recorrentes.

Vários fatores têm sido apontados como possíveis causas da evasão como: as dificuldades dos alunos na aprendizagem, a motivação dos alunos como também dos professores que não estão capacitados para ministrarem aulas às diversas modalidades de cursos que os institutos oferecem, a falta de base educacional dos próprios alunos, as aulas em períodos que dificultam na conciliação do trabalho; dificuldades estas que acarretam em elevados índices de retenção e evasão nos cursos. (Figueiredo, 2015, p. 70).

Desta forma, são quase redundantes os motivos pelos quais os estudantes evadem-se da escola, pois num país com tantas desigualdades sociais e tantas mazelas que acometem uma parcela muito grande da população brasileira, seria milagroso não ter esses eventos na escola.

Segundo Luiz Antônio Miguel Ferreira, Promotor de Justiça da Infância e da Juventude de Presidente Prudente - SP:

São várias e as mais diversas as causas da evasão escolar ou infrequência do aluno. No entanto, levando-se em consideração os fatores determinantes da ocorrência do fenômeno, pode-se classificá-las, agrupando-as, da seguinte maneira:

- $\quad$ Escola: não atrativa, autoritária, professores despreparados, insuficiente, ausência de motivação, etc.

- $\quad$ Aluno: desinteressado, indisciplinado, com problema de saúde, gravidez, etc.

- $\quad$ Pais/responsáveis: não cumprimento do pátrio poder, desinteresse em relação ao destino dos filhos, etc.

- Social: trabalho com incompatibilidade de horário para os estudos, agressão entre os alunos, violência em relação a gangues, etc. (Ferreira, n.d.).

A escola, o sistema de ensino e a educação muitas vezes ou quase sempre não oferecem atrativos para reter/manter os seus alunos e suas alunas com vontade na escola. É preciso uma espécie de força tarefa da escola enquanto instituição de ensino; da família, esta pouco provavelmente ajudaria, pois é uma das responsáveis pelo afastamento das crianças e adolescentes da escola; da sociedade; e, principalmente do Poder Público, com Políticas Públicas mais eficazes, mais eficientes e com todas as garantias que cada indivíduo precisa para exercer seu direito de se manter na escola.

As características apresentadas para que as crianças e principalmente os adolescentes evadam-se da escola são recorrentes, dado ao fato da instabilidade familiar, da baixa renda e de um processo de avaliação ainda excludente e que inibem a vontade de permanência na escola. De acordo com Rocha (2016, p. 18):

O Relatório de Desenvolvimento 2012, divulgado pelo Programa das Nações Unidas para o Desenvolvimento (PNUD), indica que um em cada quatro alunos que iniciam o ensino fundamental no Brasil abandona a escola antes de completar a última série. Esse documento revela que o país ainda tem um Índice de Desenvolvimento Humano (IDH) menor que a média dos países da América Latina, embora tenha apresentado melhoras nas últimas décadas, estando na $85^{\mathrm{a}}$ posição do ranking, levando-se em conta a expectativa de vida, o acesso ao conhecimento e a renda per capita.

Os fatores ora elencados não acontecem por mero acaso. Eles são frutos de uma defasagem de Políticas Públicas eficazes e eficientes. Mesmo tendo dado um passo à frente, o governo das esferas Federal, Estadual, Municipal e Distrital, ainda não conseguem concretizar e estabilizar os programas afirmativos inerentes ao combate a evasão e abandono escola. 
A desestrutura familiar é um fator preponderante que está no epicentro de todo esse problema, com a distorção dos valores éticos, aliados à necessidade precoce de se estar no mercado de trabalho, conjugado com a gravidez precoce na adolescência, que "rouba" as meninas do seio escolar.

Burigo (2014) afirma que: "A evasão escolar do aluno é um questão que deve envolver todos aqueles que são apontados como responsáveis pela educação (família, comunidade, sociedade em geral e o Poder Público)". Portanto é esta parceira e envolvimento em todos os âmbitos, que possivelmente poderá inibir o avanço do processo de evasão e abandono escolar.

\section{A Evasão e Abandono Escolar na Educação de Jovens e Adultos, Causas e Consequências}

Outro tema que suscita um olhar mais acurado no âmbito das Políticas Públicas voltadas para educação é o Programa de Educação de Jovens e Adultos (EJA). De acordo com o estatuído pela LDB nº 9394/96, no art. 37, “[...] a educação de jovens e adultos será destinada àqueles que não tiveram acesso ou continuidade de estudos no ensino fundamental e médio na idade própria" (Brasil, 1990).

Quando implementada, a EJA é um programa dentro da Educação Básica que vem para tentar corrigir uma dívida social que a falta de oportunidade no tempo regular de estudo não pode ser respeitada.

A educação de jovens e adultos é um avanço, mas que ainda tem muitas distorções que precisam ser corrigidas, que vão desde a questão da falta de espaço apropriado (pois muitas turmas funcionam em espaços da Educação Infantil), até a questão da merenda, exaustão por conta de uma carga excessiva de trabalho, questões familiares e vergonha por conta da desproporção idade/série.

A educação de adultos, dentro desse contexto, torna-se mais que um direito: é a chave para o século XXI; é tanto consequência [sic.] do exercício da cidadania como condição para uma plena participação na sociedade. Além do mais, é um poderoso argumento em favor do desenvolvimento ecológico sustentável, da democracia, da justiça, da igualdade entre os sexos, do desenvolvimento socioeconômico e científico, além de ser um requisito fundamental para a construção de um mundo onde a violência cede lugar ao diálogo e à cultura de paz baseada na justiça. A educação de adultos pode modelar a identidade do cidadão e dar um significado à sua vida (Declaração de Hamburgo como citado em Brasil, 2007, p. 37).

Após esta digressão em torno da Educação de Jovens e Adultos, nos ateremos ao foco que são a evasão e abandono escolar, que permeiam esta modalidade de ensino e que deixam as salas de aulas bastante vazias, comprometendo dessa forma o projeto de educação do País, atendendo ao que vem estatuído na CF/88, no seu artigo 208 que infere o seguinte: “Art. 208. O dever do Estado com a educação será efetivado mediante a garantia de: I - educação básica obrigatória e gratuita dos 4 (quatro) aos 17 (dezessete) anos de idade, assegurada inclusive sua oferta gratuita para todos os que a ela não tiveram acesso na idade própria; [...] (Brasil, 1988, grifo nosso).

Sabe-se que a EJA possui um diferencial em relação ao ensino regular com um cronograma mais flexível, que oferece ao aluno as organizações individual e coletiva, sendo que nas turmas individuais são registradas apenas as presenças do mesmo nas aulas, ou seja, o aluno não leva falta. Nas turmas do coletivo ele deve ter $75 \%$ de presença nas disciplinas. Dessa forma, o estudante matricula-se na organização que melhor se adeque a ele. O horário e turno de estudo também são escolhidos pelo aluno de acordo com a sua disponibilidade. Quanto à metodologia da EJA primase pela valorização do conhecimento de mundo do aluno, ou seja, é a partir desse conhecimento que os conteúdos são ministrados e, mesmo assim, com todas as facilidades e flexibilização do curso percebe-se o alto índice de evasão na referida instituição de ensino. (Laibida; Pryjma, 2013, s.p.).

Portanto, é significativo entender que vários são os fatores que favorecerão a evasão ou abandono na EJA. Como estão sendo tratados os casos na EJA? De acordo com Silva e Santos (2015, s.p.), "Por ser uma questão abrangente e estar 
relacionada ao problema da aprendizagem, a evasão se torna um fato que precisa ser analisado e discutido". A partir dessa inferência, quando um jovem ou um adulto saem da escola, eles perdem, porém toda a sociedade sai perdendo, pois as conquistas dos direitos sociais vão se esmaecendo, perdendo a força e consequentemente, comprometendo a cidadania estabelecida.

Vários são os motivos que levam um aluno matriculado na EJA, desistir. São pontos que devem ser trabalhados nos primeiros dias de aula e para tanto, precisa-se de um professor motivado e contextualizado com a realidade da turma em que está exercendo o ofício docente.

$\mathrm{O}$ aluno da EJA é diferenciado, porquanto precisa de uma metodologia também diferente de ensino. Eles chegam com a autoestima em baixa, pois muitos se sentem envergonhados de que na altura da vida, não sabem ler e nem escrever. A lista de motivos é extensa e precisa de uma sala acolhedora, com um professor afetivo e que tenha condição pedagógica de intervir nas demandas dessa turma. Freire (1996, p. 117), infere o seguinte: [...]. "Por isso é que, acrescento, quem tem o que dizer deve assumir o dever de motivar, de desafiar quem escuta, no sentido de que, quem escuta, no sentido de que, quem escuta diga, fale, responda".

[...] a baixa autoestima destes jovens e adultos é um dos pontos mais negativos na história de vida de cada um. A escola, para muitos, não tem sentido, pois já sofrem muito esse sentem excluídos da sociedade, sem perspectivas de vida futura. Alguns se tornam dependentes de drogas ou comerciantes deste produto para sobreviver e terminam na marginalidade ou no mundo do crime; outros abandonam a escola e buscam trabalho para sobreviver de forma digna. (Azevedo, 2006, p. 4).

Outra situação que poderá levar o aluno da EJA evadir-se ou abandonar a escola são os conteúdos programáticos, dentro do currículo. Se não houver contextualização dentro da sua realidade, a aula pode se tornar maçante e inexpressiva, proporcionando assim, a evasão. De acordo com Anzorena e Benevenutti (2013, p. 98):

O aluno precisa saber o porquê de estudar determinado conteúdo e como esse conteúdo irá auxiliá-lo(a) no dia a dia; caso não consiga estabelecer essa relação, ele, na maioria das vezes, desiste do curso. Sabemos que os casos de evasão não se restringem a um único ponto, existem outros fatores que compõem o rol de motivos.

Dentre o rol de motivos que incidem na saída dos alunos da escola, aumentando consistentemente o ranking de evasões nas escolas, está o trabalho exaustivo durante o dia, visto que como eles não têm qualificação profissional e trabalham no pesado, já chegam à escola cansados e não veem alternativas senão saírem da escola e não mais voltarem.

\section{Resultados e Discussão dos Dados}

Neste tópico serão apresentados a discussão e os resultados encontrados, através da análise das listas de frequência dos alunos da Educação Básica, englobando o Ensino Fundamental II (do $6^{\circ}$ ao $9^{\circ}$ ano) e a Educação de Jovens e Adultos da Escola Municipal "João Mendonça".

A Escola Municipal João Mendonça foi fundada em 02 de janeiro de 1994, mas só reconhecida em 12 de fevereiro de 1995 através da publicação no Diário Oficial nº 970268561 . Tem suas origens no espaço escolar antes denominado Escola de $1^{\circ}$ Grau Vereador Geraldo Roni (conhecida pela comunidade local como rocinha por ser localizada à época em zona rural) onde atualmente funciona a UNEB - Universidade do Estado da Bahia, em Teixeira de Freitas-Bahia.

O motivo da escolha da referida escola se justifica pelo fato da mesma abarcar tanto o Ensino Fundamental II quanto a Educação de Jovens e Adultos (EJA), com um volume muito grande de alunos matriculados, atendendo desta forma os 
objetivos envidados para o tema proposto. Não poderia ter fonte melhor, pois atendeu todas as nossas expectativas de pesquisadores.

Fizemos um recorte temporal entre os anos de 2014 a 2018. Os resultados serão mostrados através dos gráficos disponibilizados abaixo, com os dados de cada ano estabelecido na pesquisa e mais um gráfico geral da quantidade de matrículas e evasões.

Ao analisarmos o Gráfico 1 referente ao ano de 2014, percebemos que a Educação de Jovens e Adultos (EJA), teve um total de 353 matrículas e um total de 87 evasões, enquanto que no Ensino Fundamental II, a taxa de matrícula perfez um total de 399 alunos e 14 evasões. Percebemos que na EJA a taxa de evasão nesse ano foi muito grande, superando o E.F.II.

Gráfico 1. Ano 2014.

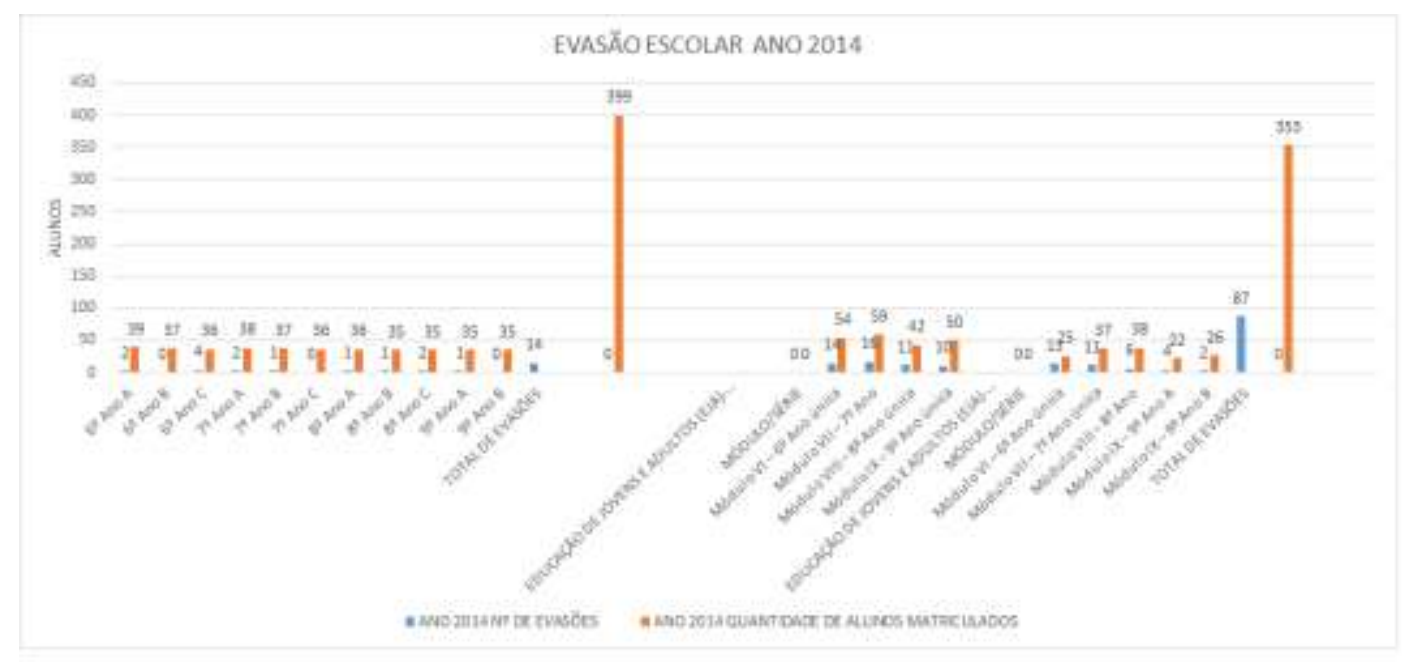

Fonte: Autores (2020).

De acordo com o Gráfico 2, referente ao ano de 2015, localizado abaixo, verificamos que a escola teve na EJA 355 matrículas e o E.F. II atingiu a marca de 379 matrículas e 13 evasões. 
Gráfico 2. Ano 2015.

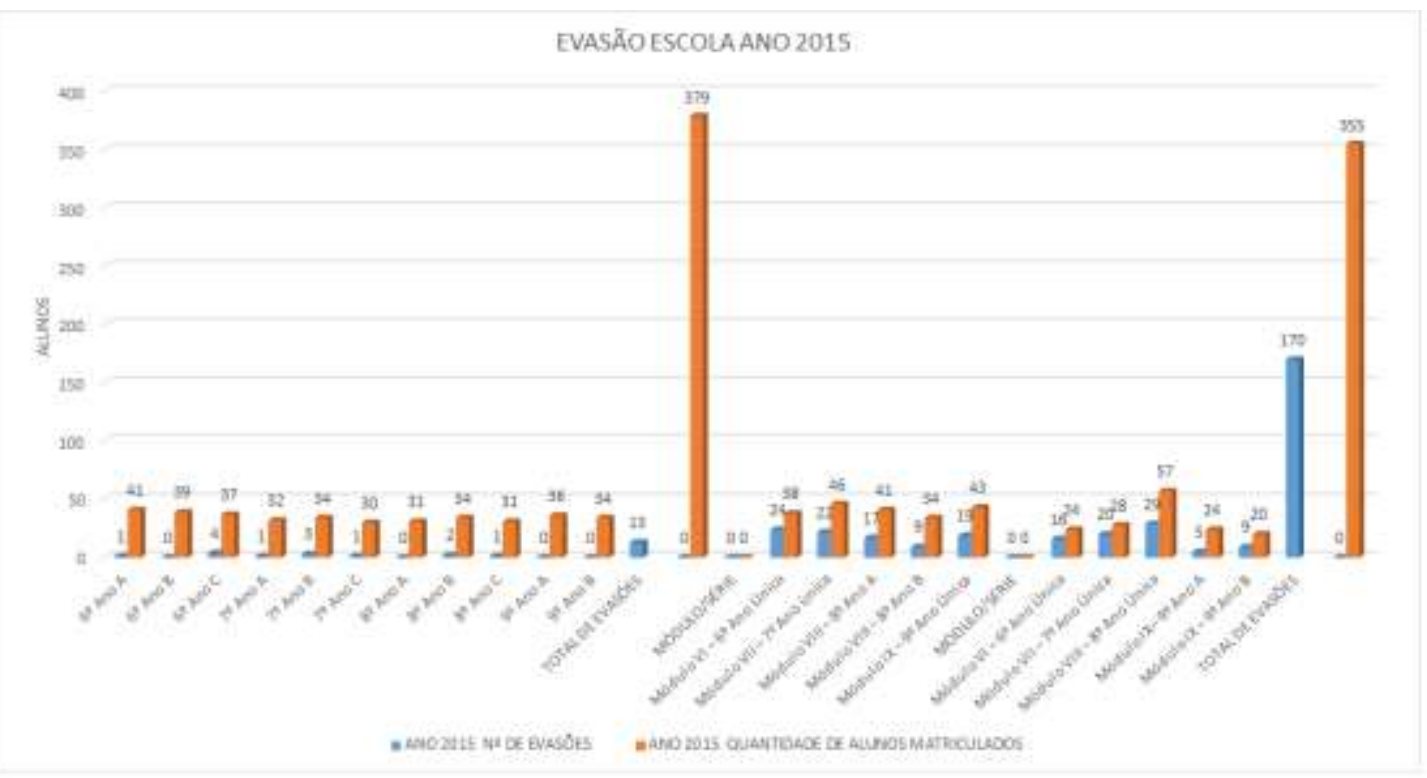

Fonte: Autores (2020).

Avançando para o ano de 2016, o Gráfico 3 nos aponta que foram feitas 315 matrículas na EJA, com um total de 95 evasões. Já o E.F. II registrou 449 alunos matriculados e 09 evadidos.

\section{Gráfico 3. Ano 2016.}

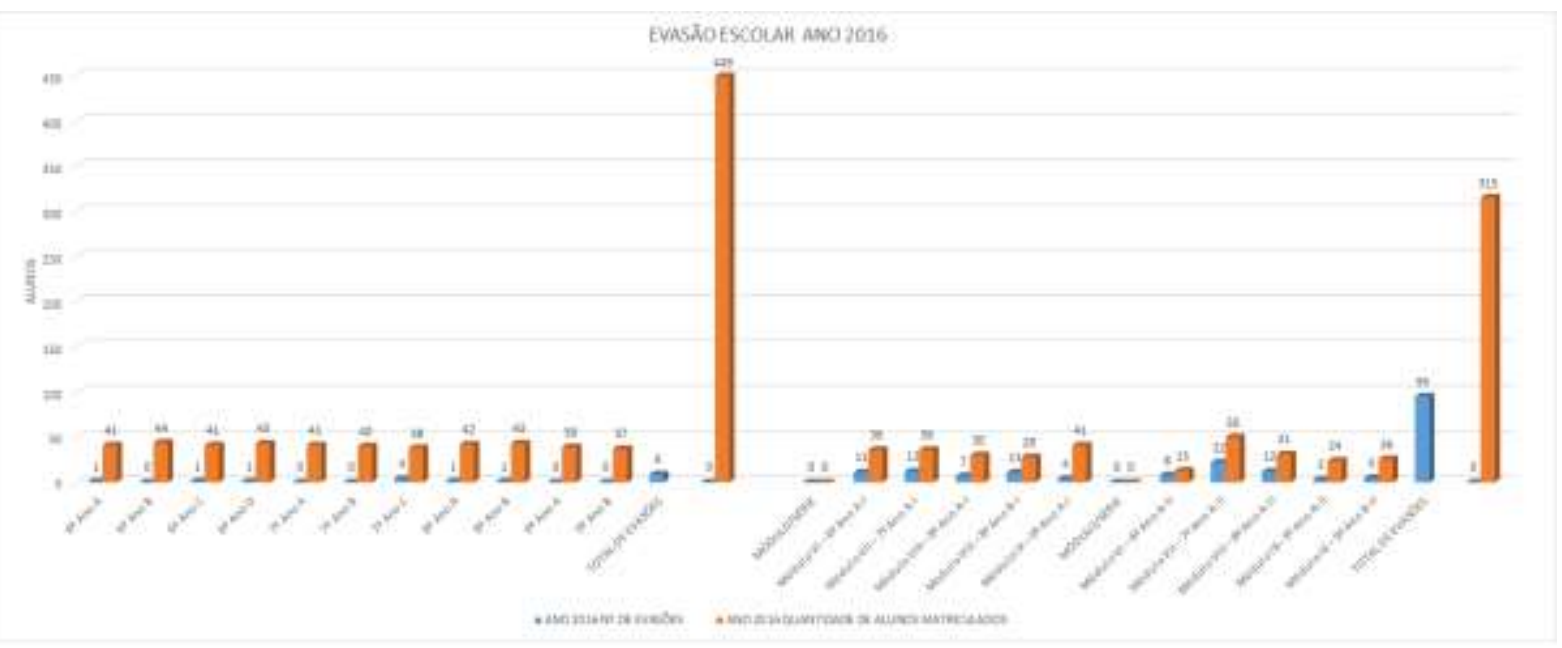

Fonte: Autores (2020).

Conforme os dados apontados no Gráfico 4, pudemos verificar que no ano de 2017 a EJA teve 340 pessoas matriculadas e um total de 113 evasões. Ao mesmo tempo em que no EF II as matrículas perfizeram um total de 434 alunos e 8 evasões. 
Gráfico 4. Ano 2017.

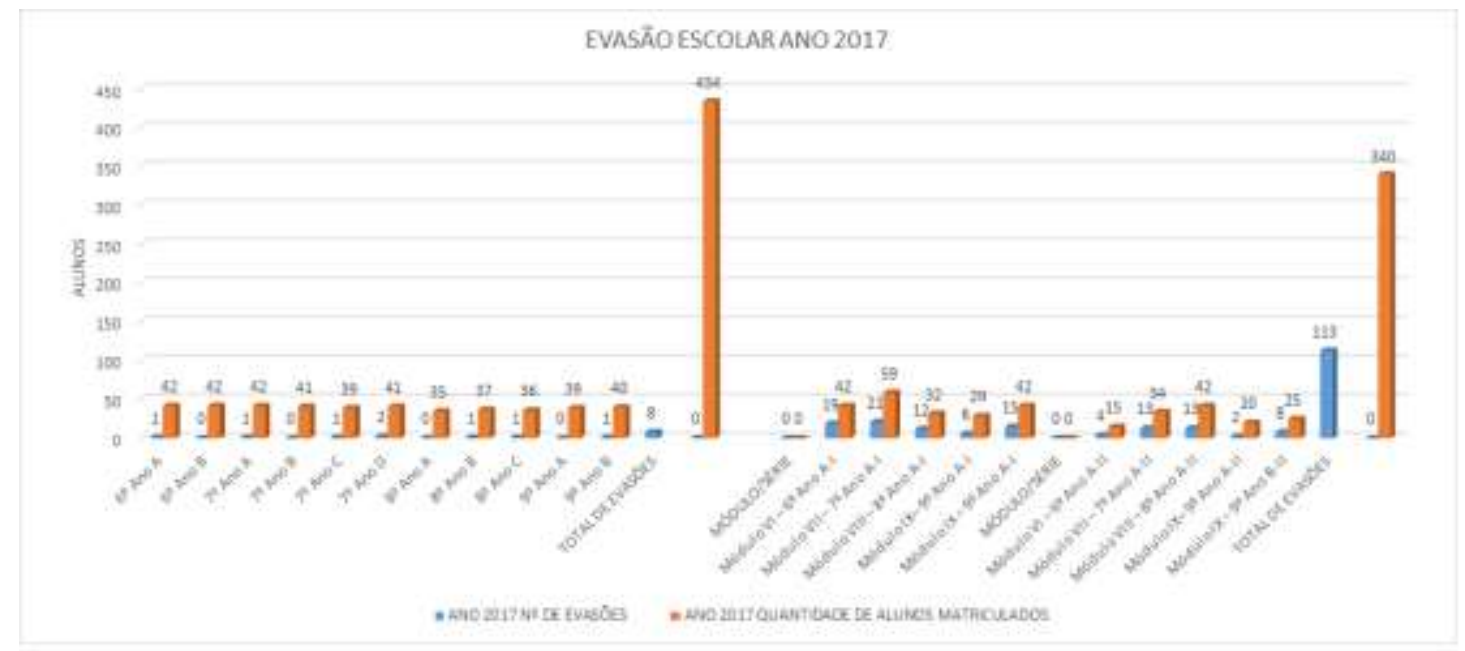

Fonte: Autores (2020).

No ano de 2018, o número de matrículas na EJA foi de 86 alunos e de evasões foram apuradas 44 evasões. O E.F. II registrou um total de 397 matrículas e 22 evasões.

Gráfico 5. Ano 2018.

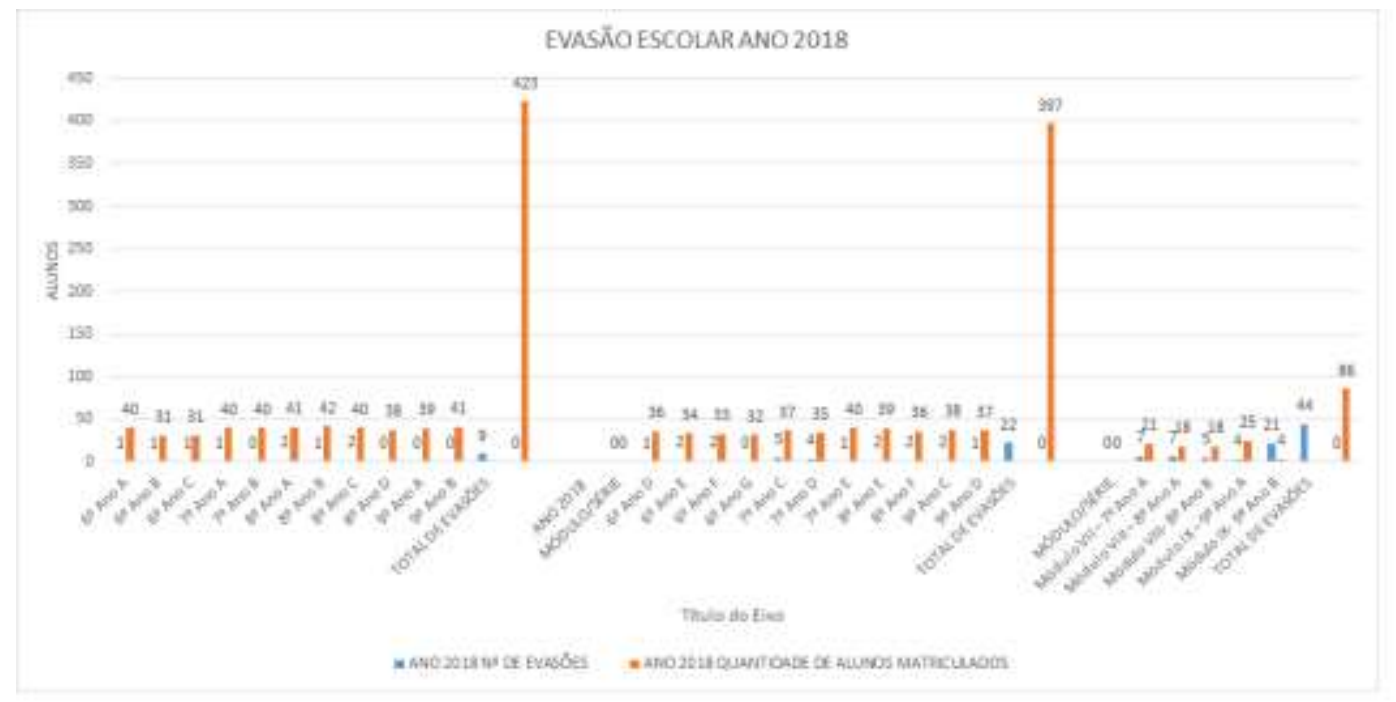

Fonte: Autores (2020).

Finalizando a apresentação desses números através dos gráficos elencados no trabalho, fruto de uma pesquisa in loco, na Escola Municipal “João Mendonça”, em Teixeira de Freitas-Bahia, respeitando o recorte temporal estabelecido através dos anos 2014 a 2015, para obtenção dos resultados esperados, disponibilizamos o Gráfico 6 que traz o número total de alunos 
matriculados e evadidos, nos dois seguimentos da Educação Básica, perfazendo um total geral de 3.932 matrículas e 584 evasões.

Gráfico 6. Anos 2014 A 2015.

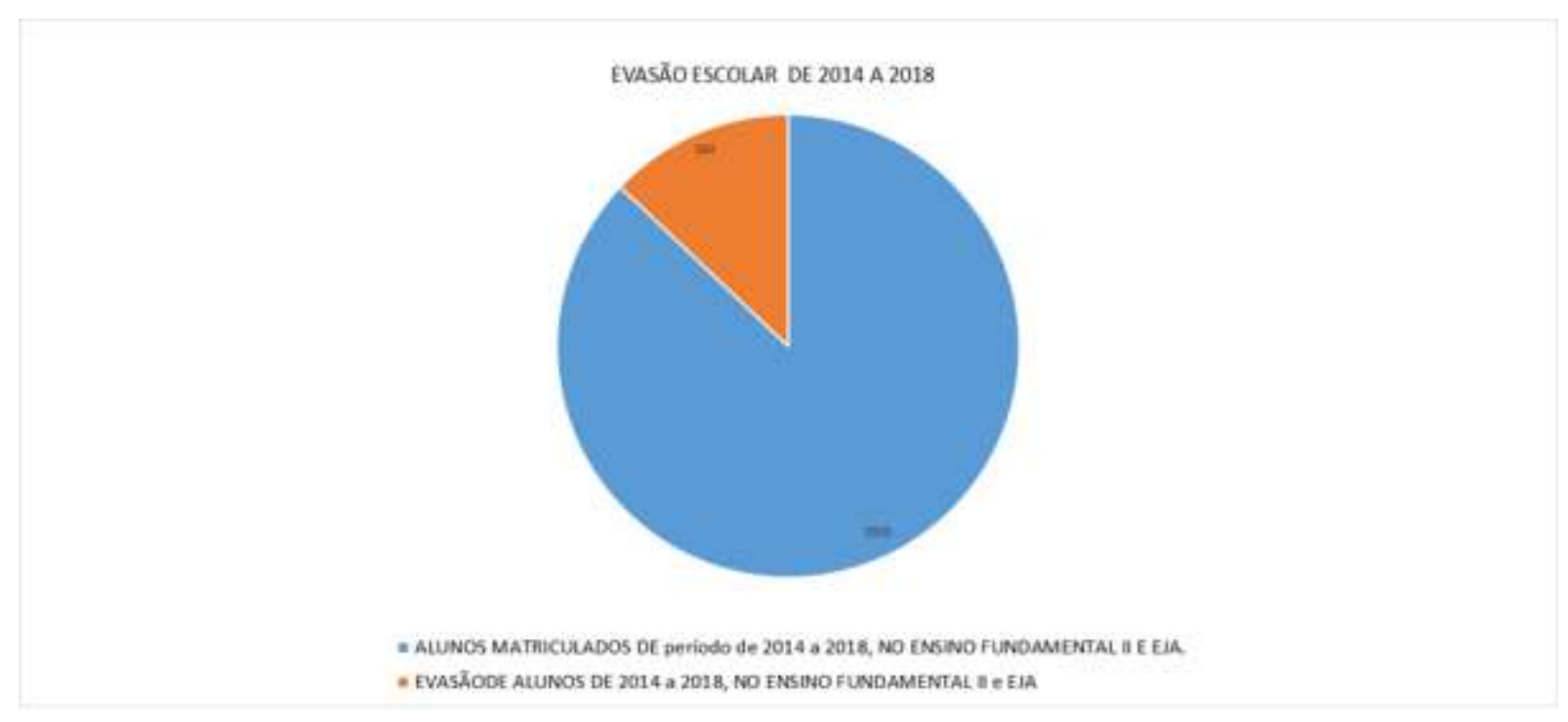

Fonte: Autores (2020).

Como resultado, verificamos que o número maior de alunos evadidos está concentrado na EJA. Já no Ensino Fundamental II, o número é menor, mas não deixa de ser preocupante, pois lugar de criança e adolescente é na escola.

Ao perguntarmos à diretora se havia casos de evasão na Escola "João Mendonça", ela nos respondeu o seguinte:

"Evasão no diurno é muito pouca. No diurno a gente não vê esse problema não, é muito pouco. Até porque quando a gente descobre o professor sinaliza e a direção e coordenação já começa ligar para os pais avisando. E daí vem aquela questão do Programa Bolsa Família; a gente já liga e dá aquela ameaçada. Olha, já faltou tantos dias, e aí acaba voltando.

Agora no noturno, na EJA é que nós temos sim um grande índice de evasão, principalmente o segundo semestre. A EJA é dividida em dois semestres. No primeiro semestre de janeiro a junho a gente tem bastante aluno aqui na EJA. De julho até dezembro, aí já tem uma evasão. Devido ao horário de trabalho deles, muitos estão cansados, aí também tem a questão do ENCEJA, que como eles já vão fazer e acreditam que vão passar, já desistem. Outros se desmotivam. Foi feita uma pesquisa no noturno e se descobriu que uma coisa que faz eles ficarem na escola é a merenda salgada todos os dias. Então foi um desejo deles que todos os dias tivesse essa merenda. Infelizmente nós não podemos oferecer todos os dias essa merenda salgada. A gente tenta oferecer duas vezes na semana. Porque o que nós recebemos dá para fazer isso aí. Ano passado oferecíamos três vezes na semana. (Campos Ferreira, L., 05 de novembro de 2018).

Como resultado, de acordo com os gráficos acima e a fala da diretora da escola objeto dessa pesquisa, a evasão, principalmente na EJA, ocorre por diversos motivos, mas os principais orbitam em torno da necessidade de trabalharem; da falta de uma merenda salgada, pois muitas vezes esses alunos saem direito do trabalho para a escola e não têm tempo de irem até em casa tomarem um banho e fazerem uma refeição mais reforçada.

Já os adolescentes quando evadem, o fazem porque precisam ajudar nos afazeres domésticos e trabalhar para ajudar nas despesas de casa; tem também falta de dinheiro para as despesas, falta de alguém que os motivem ou cobrem a sua ida para escola e gravidez na adolescência, inviabilizado a permanência na escola.

As crianças quando a família não participa efetivamente do seu processo educativo, a tendência, embora em número menor, é evadirem. 
Portanto, os eventos que ocasionam e motivam a evasão e o abandono escolar, estão intrinsecamente ligados aos vários fatores elencados acima, como se fossem um "efeito cascata" e necessitam com urgência de uma rede de apoio e políticas públicas consistentes, participação da sociedade em geral, da família e do Estado, para que haja a consolidação e pulverização da educação abarcando todo cidadão brasileiro - crianças, adolescentes, jovens e adultos.

\section{Considerações Finais}

Dissecar sobre esse assunto não foi a nossa pretensão, pois, configura-se como um chamamento para que outras pessoas possam se inspirar no combate a um assunto pouco falado, com pouca literatura e poucas pesquisas, mas que vem repercutindo de maneira negativa na educação brasileira.

O tema evasão é deveras pouco corriqueiro no meio político, educacional e social. $\mathrm{O}$ amparo ao evadido e às famílias ainda é muito incipiente. Demanda boa vontade, discussão, planejamento e muita pesquisa, para que entendamos os entraves e as descobertas que envolvem tal tema. As estatísticas falam por si só, mas precisamos tirar nossas vendas dos olhos e fazermos uma reflexão do que esse tema enseja.

Um país com uma riqueza e uma cultura tão diversificada não pode, pensamos assim, dar as costas para um problema com tamanha envergadura e gravidade. Educação precisa ser tratada com seriedade, aportes financeiros (governo) e consciência social (sociedade e família).

Ao tratarmos sobre o tema Evasão e Abandono Escolar, sabemos que existem outros fatores que dão incidência direta a esse problema. São várias as nuances que emperram o processo educacional, principalmente na educação de jovens e adultos, mesmo com um programa específico para este público, que traz consigo a baixa autoestima, a desmotivação e a necessidade prematura de entrar no mercado de trabalho.

Outros problemas graves que tiram muitas adolescentes da escola é a gravidez precoce; drogas, geralmente usada pelos meninos em sua maioria; falta de motivação pela família; ausência dos pais; lares desestruturados, etc. Tudo isto contribui incisivamente para que crianças, adolescentes, jovens e adultos saiam da escola e para ela normalmente não voltam, a despeito de uma legislação garantidora.

Portanto, o assunto é preocupante, pois por detrás de todo o processo de saída das crianças, adolescentes, jovens e adultos da escola, etc. entendemos que existem fatores que contribuem incisivamente nessa não permanência, comprometendo o ensino e aprendizagem e o futuro da educação no Brasil.

Quando suscitamos esses questionamentos e pesquisamos as causas e consequências da evasão e abandono escolar tivemos o intuito de engrossar a fila dos teóricos, pesquisadores e educadores que pretendem mitigar esses eventos e num futuro próximo zerar todos os casos que impedem da educação evoluir aqui no Brasil.

Para que haja a efetivação sistêmica dos direitos de todos não só ingressarem na escola, mas permanecerem, as Políticas Públicas para a educação não têm que ser voltadas apenas para o aluno dentro da escola, mas para o entorno dessa escola e desse aluno, com projetos que busquem identificar todas as mazelas recorrentes que permeiam a evasão e abandono, e que promova a permanência desse aluno da escola.

Sugerimos que se pesquisem mais sobre o tema, pois este não está exaurido visto que a sua literatura ainda é incipiente e necessita de mais teóricos debruçados sobre o assunto.

A atenção dos gestores públicos, dos gestores escolares, professores, família e sociedade em geral, deve ser redobrada para o contingenciamento desse problema que acomete os adolescentes, jovens e adultos, impedindo-os, cada um com sua causa, de terem um futuro mais promissor e inclusivo de oportunidades. 


\section{Referências}

Anzorena, D. I., \& Benevenutti, Z. M. S. (2013). Educação de Jovens e Adultos. Uniasselvi.

Azevedo, F. V. M. de. (2006). Causas e consequências da evasão escolar no ensino de jovens e adultos na escola municipal Espedito Alves, Angicos/RN. Dominium: Revista Científica, Natal, http://webserver.falnatal.com.br/revista_nova/a4_v2/index.php

Burigo, E. R. (2014). A Evasão Escolar nas turmas de $8^{\circ}$ e $9^{\circ}$ anos do Ensino Fundamental do Colégio Novo Horizonte no município de Toledo- PR no ano letivo de 2013: causas, consequências e possibilidades de intervenção. Secretaria de Estado da Educação - Programa de Desenvolvimento Educacional do Paraná- Universidade Estadual do Oeste do Paraná- Os Desafios da Escola Pública Paranaense na Perspectiva do Professor PDE- Produções DidáticoPedagógicas - Cascavel.

Constituição da República Federativa do Brasil. (1988). Constituição da República Federativa do Brasil: Senado. http://legis.senado.leg.br/norma/579494/publicacao/16434817

Declaração de Hamburgo (2007). Educação de Jovens e Adultos: uma memória contemporânea, 1996-2004. Org. PAIVA, Jane; MACHADO, Maria Margarida; IRELAND, Timothy. Declaração de Hamburgo sobre Educação de Adultos - Brasília: Secretaria de Educação Continuada, Alfabetização e Diversidade do Ministério da Educação, Organização das Nações Unidas para a Educação, a Ciência e a Cultura.

Digiácomo, Murillo José. (2005). Evasão escolar: não basta comunicar e as mãos lavar. http://www.crianca.mppr.mp.br/pagina-825.html

Estatuto da Criança e do Adolescente (1990). Lei no 8.069 de 13 de julho de 1990. Dispõe sobre o Estatuto da Criança e do Adolescente e dá outras providências. Senado. http://www.planalto.gov.br/ccivil_03/leis/18069.htm

Ferreira, A. B. de H. (2001). Mini Aurélio Século XXI Escolar: O minidicionário da língua portuguesa. (4a ed.), Nova Fronteira.

Ferreira, L. A. M. (s.d.). Evasão Escolar. Promotor de Justiça de São Paulo. https://docplayer.com.br/18021439-Evasao-escolar-luiz-antonio-miguel-ferreirapromotor-de-justica-sp.html

Figueiredo, K. N. dos R. W. de A. (2015). Evasão Escolar: um estudo de caso no Instituto Federal de Educação, Ciência e Tecnologis do Tocantins - Campus Porto Nacional. Curso de Mestrado do Programa de Pós-Graduação em Educação, 2015.

Freire, P. (1996). Pedagogia da Autonomia: saberes necessários à prática educativa. Paz e Terra.

Gil, A C. (2010). Como elaborar Projetos de Pesquisa. (5a ed.), Atlas.

Kuroski, C. (2013). Políticas Públicas na Educação Básica. Uniasselvi.

Laibida, V. L. B., \& Pryjma, M. F. (2013). Evasão escolar na Educação de Jovens e Adultos (EJA): professores voltados na permanência do aluno na escola. Os Desafios da Escola Pública Paranaense na Perspectiva do Professor - PDE. Artigos, vol. 1- Versão On-line ISBN 978-85-8015-076-6, Paraná.

Lei de Diretrizes de Bases de Educação Nacional- (1996). - Lei no 9394 de 20 de dezembro de 1996. Estabelece as diretrizes e bases da educação nacional. Diário Oficial da República. http://www.planalto.gov.br/ccivil_03/leis/L9394.htm

Lei 10.287 de 20 de setembro. (2001). Altera dispositivo da Lei $\mathrm{n}^{\circ}$ 9.394, de 20 de dezembro de 1996, que estabelece as Diretrizes e Bases da Educação Nacional. http://www.planalto.gov.br/ccivil_03/leis/leis_2001/110287.htm .

Mendes, I. L. (2016). Produção Didático-Pedagógica: a evasão escolar no Ensino Médio. Universidade Estadual de Londrina - Programa de Desenvolvimento Educacional da Secretaria de Estado de Educação Paraná.

Oliveira, P. S. de. (2005). Introdução à Sociologia da Educação. (3a ed.), Ática.

Piaget, J. (2007). Para onde vai à educação? José Olímpio.

Riffel, S. M., \& Malacarne V. (2010). Evasão escolar no ensino médio: o caso do Colégio Estadual Santo Agostinho no Município de Palotina, PR.

Rocha, J. B. da. (2016). O direito à educação no Município da Serra/ES: análise do Programa Pró-Escola. Curso de mestrado do Programa de Pós-Graduação em Ensino da educação Básica (PPGEEB), São Mateus.

Silva, A. da G., \& Araújo, T. B. de. (2014). Relação Família e Escola. Trabalho de Conclusão de Curso, Licenciatura em Pedagogia. Cantro Educacional Eliã - CEEL. https://pt.slideshare.net/JJOAOPAULO7/tcc-relao-famlia-e-escola

Silva, E. M. da N., \& Santos, J. O. dos. (2015. Evasão escolar: um problema, várias causas. REBES - Revista Brasileira de Educação e Saúde. 5(4), 30-35.

Silva Filho, R., \&Araújo, R. M. de L. (2017). Evasão e abandono escolar na educação básica no Brasil: fatores, causas e possíveis consequências. Educação por Escrito. 8(1), 35-48.

Souza, M. C. de. (2010). Direito Educacional. Editora Verbatim. 